\section{THE PRESSURE ERRORS OF THE "CHALLENGER" THERMOMETERS 1} I.

\section{The Pressure-Corrections supplied to the "Challenger" along}

WHEN I was first asked to examine the thermometers I judged, from the appearance and nature of the protection over the bulbs, that very slight corrections only would be required, even for the greatest pressures to which they had been exposed. But Sir Wyville Thomson told me that a correction of at least half a degree Fahr. had been assigned for them for every mile under the sea. This correction had been given him by Capt. Davis of the Admiralty, who had in his experiments ${ }^{2}$ the assistance and advice of such exceedingly able experimenters as the late Prof. W. Allen Miller and others.

Hence, although it appeared to me at first sight incredible that any such correction should be required for thermometer; with protected bulbs, I considered it absolutely necessary to try Capt. Davis' experiments over again, under the same conditions as those which he had adopted in conjunction with Prof. Miller. My object was, of course, to find out whether I could again obtain these results, and, if I could obtain them, to discover what were the causes which led to their being so exceedingly different from what I should have expected. I felt assured that the results were much too large; - and I had therefore, if I could reproduce them, to trace the various possible causes of divergence between the results of experiments conducted in a hydrostatic press and of other similar experiments made at the same pressures in the deep sea.

Half-a-degree Fahrenheit per mile of depth may seem to be a matter of very little consequence; but when we recollect that some of the Challenger soundings were made at depths nearly approaching six miles, we find that we have sometimes to deal with a correction of $3^{\circ} \mathrm{F}$., enough to modify seriously our theories of ocean circulation. For it can never be too strongly impressed on the student of science that there is no such thing as greatness or smallness in itself; what is very small relatively to one class of quantities may be very great relatively to another and different one. All the temperature differences, except near the surface of the sea, though important in their consequences, are very small relatively to differences of temperature in the atmosphere ; but, just because they are so small, small errors in the determination of their values are important:-thus it was imperative to decide whether the corrections assigned by Capt. Davis are necessary.

At first sight one might think that by far the best way of conducting an inquiry of the kind would be to carry it out under circumstances nearly the same as those of the Challenger observations. No doubt, if we had at hand a coal-pit or mine-shaft full of water, and of six miles or so in depth, we might make the experiments without the aid of presses, and under circumstances far more favourable than those in which I was obliged to operate. The reasons for this statement will appear presently. There are great objections to making test-observations at sea. The Challenger observations themselves had, of course, to be made at sea, but to make under similar circumstances experiments for the purpose of determining corrections would be a perfectly hopeless attempt. The circumstances under which thermometers are let down and drawn up again at sea are extremely unfavourable to accuracy of observation. I had, therefore, to content myself with such conditions as could be procured by means of hydrostatic presses.

II. Construction of the Thermometers. - I will now say a word or two about the construction of the thermometers themselves; and I shall thus have an opportunity of pointing out some of the peculiarities of construction to which I have traced the greater part of the very large effects obtained by Capt. Davis, and given by him as corrections which required to be made.

The Challenger thermometers are all of the Six pattern : there is a highly expansible liquid in the large bulb, which projects to a certain extent into the narrow U-tube. Then there is a column of mercury occupying the bend of the $U$ and part of each stem. Above that, on the maximum side, there is some more of the

${ }^{x}$ By Prof. Tait. Abridged by the Author from a forthcoming volume of the Reports of the Voyage of H.M.S. Challenger, by permission of the Lords Commissioners of H.M. Treasury.

2 "On Deep-Sea Thermometers," by Capt. J. E. Davis, R.N. (Proceedings of the Meteorological Society, April 1871). sensitive liquid ; and at the ends of the mercury column are the maximum and minimum indices, each containing a piece of steel, so that they can be set by means of an external magnet. The large bulb on which the temperature effects are mainly produced is protected by an exterior shell of glass strong enough to resist a pressure of at least 5000 fathoms of sea-water; that is to say, approximately, somewhere about six tons weight per square inch. This external shell is nearly filled with alcohol. The main difference between this and the first invented form of protected thermometer, which (so far as I know) was introduced by Sir William Thomson, ${ }^{1}$ is simply that the bulb only is protected, the stem being exposed, and therefore the effects produced directly by compression are due solely to the stem of the instrument: unless, indeed, there be a strain produced on the protected bulb (altering its volume) by the wry-neckedness of the protecting shell.

Now, as a rule, till quite recently, practical workers in glass supposed that no effect at all would be produced by pressure upon an ordinary thermometer stem, simply because the external diameter is so much greater than the internal; and, in fact, so little was the nature of the effects of hydrostatic pressure known to practical glass-blowers that one of Mr. Casella's workmen undertook in 1869 to furnish Capt. Davis with thermometers whose bulbs should be so thick as to "defy compression"! It will be seen presently that such an idea is entirely absurd :that, however thick is an unprotected thermometer, it will still have its indications altered by compression, and very nearly as much as a thinner one, unless that be extremely thin. So far as the Challenger instruments are concerned, the only effect that can be expected to be produced directly by pressure is the diminution of the bore and length of the narrow tube, and the consequent forcing of the liquid which occupies it to fill a greater length in' it. I made at starting a rough calculation of the amount of effect of this kind which was to be expected; taking average data as to the compressibility and rigidity of glass. I found it to be a small fraction only of a degree for each ton-weight of pressure, except on those thermometers which had very short degrees. It was clear to me, therefore, that (unless the wryneckedness already mentioned was the cause) the larger part of Capt. Davis' result was not due to pressure directly.

1II. Wholly Protected Instruments. Their Defect.-For the purpose of comparison with the Challenger instruments, so far as regards the effect on the unprotected stem, Sir Wyville Thomson sent me two mercury thermometers constructed after Sir William Thomson's device. In these instruments the whole, bulb and stem alike, is inclosed in a strong glass tube, nearly filled with alcohol. The effects of pressure on these instruments were very much smaller than on the thermometers of the Challenger. This result was so unexpected that I at first thought it due to defects in the new instruments. But, as will be seen later, it is quite consistent with the final result of my investigations. It is, however, very difficult to obtain good results from these instruments under the circumstances in which I was working. Their recording adjustment is constructed on a new plan, in which a little portion of mercury is detached from the rest; and separated from it by a small quantity of air, which does not move it until compressed to a definite amount. To set the index before an observation, the instrument has to be swung round somewhat sharply at arm's length. It was scarcely ever possible under these circumstances to adjust it to the temperature of the water in the press. The indices in the Challenger thermometers, on the other hand, consist each of a piece of enamel with a couple of hairs attached to it so as to fix itself in the tube and retain a record of the observation. They have also a little piece of needle inside, and can thus be moved from the exterior by means of a horse-shoe magnet, so that the adjustment can be made at pleasure, and without any alteration of the temperature. The thermometers are plunged for some hours in the water in the press, and the indices are set in an instant while the instrument is partially lifted out for the purpose. With the other instruments one might spend days before he could get them

I "The Effect of Pressure in Lowering the Freezing-point of Water experimentally demonstrated," by Prof. W. Thomson (Proc. R.S.E., February 1850). See also the paper by Parrot (1833) quoted below. In this a protected thermometer was undoubtedly employed; but the protecting sheath tected thermometer was undoubtedly employed; but the protecting sheath
was part of the wall of the compression apparatus and was not attached to was part of the wall of the compression apparatus and was not attached to
the thermometer itself. From a reference in this paper I was led to consult the thermometer itself. From a reference in this paper I was led to consult
Lenz' observations on deep-sea temperatures. He appears to have measured Lenz observations on deep-sea temperatures. He appears to have measured
these temperatures by bringing to the surface, with great care, a considerable these temperatures by bringing to the surface, with great care, a considerable
quantity of water from each depth. There was a thermometer in the collecting apparatus, with a bulb of extra thickness; but no recording index was employed, so as to show what was its indication under pressure. 
introduced, except after special cooling, into the press with the index suitably adjusted to the temperature of the water. The whole difficulty might have been avoided by putting an exceedingly small piece of iron or steel wire above the index, to be acted on by a sufficiently powerful magnet.

Thus, although these instruments are absolutely perfect so far as regards immunity from pressure (and in other essential respects which will be mentioned later), it is not easy to work with them under the circumstances of this investigation.

IV. Individual Peculiarities of some of the "Challenger" Thermometers. - The Challenger thermometers are not all exactly similar to one another. Some of them have their degrees very much longer than others; others have the extraordinary peculiarity that the degrees upon the maximum side are nearly half as long again as those on the minimum side, and sometimes it is the reverse. In one of the instruments which was occasionally used in the deep sea, the length of a single degree on the maximum side is only about three-fourths of a millimetre, and thus a reading to a tenth of a degree is not to be looked for. But on account of this unexpected peculiarity this particular instrument was of use, as will be seen later, in demonstrating that the effects produced in the press were due partly to heating, partly to compression. Several instances of useful peculiarities of a similar character were detected, and utilised.

In fact, the instruments cannot be said to do more than furnish rough and ready means of approximating to temperatures within about a quarter of a degree, or in the most favourable circumstances a tenth of a degree Fahrenheit. Had they been more nearly what would be called "scientific" instruments, they might have altogether failed on accsunt of the rough treatment to which they were necessarily subjected during $\mathrm{u}$ :e. Letting them down into the sea presents in general no great difficulties, but when they have to be hauled on board again they are subject to jerks and shocks, and sometimes swing through large arcs at the end of the lead line. Such misadventures are unavoidable at sea, and are excessively unfavourable to accurate results, because the index is necessarily not fitted so tightly in the stem that it may not in a few oscillations be sensibly displaced. And there is a defect inseparable from the use of movable indices:-viz. that the reading of the mercury column is sensibly different according as the index is, and is not, in contact with it. The capillary convexity affects the maximum and minimum indices in opposite ways.

Further, I may observe (though it does not affect my work) that in these thermometers the scale is at some distance from the mercury in the stem, and no provision is made for avoiding parallax or personal equation. By merely altering the position in which one holds the thermometer, it is possible to read the temperature whether by the mercury column or the end of the index next it, to an amount different in some of the thermometers by as much as a quarter of a degree, and in the great majority of them by as much as a tenth. Thus if we get readings con sistent within a tenth of a degree we get all that the instruments are capable of furnishing. I have therefore always read the thermometers in exactly the same position and (when so much accuracy was attainable) only to the nearest tenth of a degree. And I have always made my comparisons between successive positions of the index; the only readings of the mercury directly being taken roughly to find whether any permanent temperaturechange had been produced in the water of the press by pressure or otherwise, during the course of an experiment.

A great many different materials were tried for the framing of the thermometers: and vulcanite was finally chosen, having been found to answer the purpose exceedingly well. Wood warped, and metal was unsuitable for various reasons. It is rather curious to find, as will be seen below, that this substance was one of the main causes of the very large amount assigned to the pressure-correction.

V. Capt. Davis' Mode of Testing; and his Correction for the Maximum Side.--It is necessary to look somewh t closely into the mode in which Capt. Davis conducted his experiments, in so far at least as it differs from the one I afterwards employed ; in order that we may be able to form an idea how, with nearly all the facts before him, he yet failed to get their proper interpretation. Take, for instance, the way in which he attempted to determine the correction which is due to the heating of water by compression. This, of course, affects the thermometers while in the hydrostatic press, but not when they are let down into the sea. When the water in the press is compressed with the thermometers in it, it becomes hotter as the pressure increases (so long at least as its temperature is above $4^{\circ} \mathrm{C}$. or $39^{\circ} \cdot 2 \mathrm{Fahr}$, that of its maximum density). This is quite analogous to the heating of air in a cylinder when a piston is suddenly forced down; when, as every one knows, tinder can be kindled by the heat developed. So water is heated by compression, but not to anything like the same extent. But it is necessary to remark that the amount of heating of water by a given compression depends in a very curious manner upon the original temperature of the water. For water taken at its maximum density is neither heated nor cooled by compression, but it is heated by compression if it is at a temperature higher, and cooled if it is at a temperature lower, than that of the maximum density. One set of Capt. Davis' observations were made in water at temperatures near, but under, the maximum density point: in which, therefore, very little effect can be produced, even by very great pressure (and that little should be cooling, not heating), and he combined these with a number of other observations made at temperatures approaching $55^{\circ} \mathrm{F}$, , in which a comparatively large amount of heat. ing is produced even by moderate pressures. The average of the results of these determinations was taken, but, unfortunately, Capt. Davis struck out before taking the average all those observations which appeared to give much larger eftects than the others, taking them as being obviously erroneous.

When we sift out from the observations all those made nearly at any one temperature we find they agree fairly enough with the theoretical result of the compression. But observations made at different temperatures were included in the group from which the average effect was deduced. Such an average has no physical meaning.

Capt. Davis concluded from two sets of observations, one at $55^{\circ} \mathrm{F}$. and the other about $39^{\circ} \mathrm{F}$., that little attention need be paid to the heating of water by compression, and thus that the effect observed in the hydraulic press was due mainly to direct pressure, and would, of course, be experienced by the thermometers when they were let down into the sea.

The officers who managed the thermometers of the expedition, were, in consequence, furnished with corrections for each thermometer, all of the order already indicated, i.e. about half a degree for each mile under the surface of the sea. These corrections were, of course, for the maximum side of each instrument.

VI. Consequent Correction for the Minimum Side.-Looking at the thermometers, it seemed to me perfectly evident that this correction, if it was to be applied at all, must be applied in very nearly the same amount both to the maximum index, for which it was determined, and also to the minimum. Any difference between these two must be due solely to the effects of tempera. ture upon the column of mercury which lies between the two indices, and of pressure on the tube containing that mercury. Unless the heating effect were confined to the space between the indices, the former is provided for by the graduation of the instrument itself ; and it was quite certain that the two together could not produce an effect amounting to more than a small fraction of the degree and a half for three tons pressure.

Therefore, as all the readings of the Challenger thermometers were taken from the minimum index, they were subject, accord. ing to iny interpretation of Capt. Davis' results, to a correction of very nearly half a degree Fahr. for every mile of depth.

Now, even if the heating effect on the water in the press had been correctly determined, the result would have led to a deduction of at the utmost only about one-fourth of the whole correction, thus still leaving a very formidable correction indeed.

VII. Theoretical Determination of the Direct Effect of Pressure. Experimental Verification.-I therefore calculated the effect of pressure on a thermometer tube, assuming the best data for the compressibility and the rigidity of glass. The result, so far as is required for the present argument, is that the internal capacity of a glass tube (whose walls are thick in comparison with the diameter of the bore) is reduced by about $I$-Icooth part for each ton weight (per square inch) of pressure applied from without the ends being closed. Hence, if such a tube be partly filled with mercury, with an index above it; the index should be displaced by $I$-Ioooth of the length of the column of mercury for each ton weight of pressure applied to the outside of the tube

I tried the experiment with a thermometer tube, the length of the mercury column being as nearly as possible a metre, and I found for every ton-weight of pressure to which the tube was exposed the index was displaced by one millimetre, the I-Ioooth part of the length of the column precisely, being far more nearly than I had expected the result I had already calculated from 
theory. Since, then, there is only a change of one-thousandth in the length of the column, it is quite obvious that the amount of effect produced upon the column of mercury in the Challenger thermometers (which is not above a sixth or a seventh of a metre in length at the utmost), that is to say, the whole correctiondifference between the maximum and minimum indices is a matter of a sixth or seventh of a Dillimetre; or in general very nearly the same fraction of a degree of the scale. Thus it is proved that the correction supplied by the Admiralty, if it is to be applied at all, ought to be applied almost in its entirety to the minimum index.

VIII. The Aneurisms. Their Object and Effects.-There is another peculiarity of the Challenger thermometers, which leads to a slight-but only a slight-modification of this statement, viz. that at the lower end of each of the two vertical columns there is an aneurism on the tube. These form a sort of secondary bulb, making the tube faulty again after the primary bulb has been protected. Their effect is slightly to increase the effective length of the column of mercury.

I learned from Sir George Nares that the object of these aneurisms, and of another which is situated close to the bnlb, is to prevent the indices from being jammed at the bends of the stem, or forced into the bulb, when the instrument is expo:ed to very high or very low temferatures. 'I hey seem to be in every respect objectionable, especially as the necessity for them would be entirely removed by adding an inch or two to the length of the instrument ; or, if they must be retained, by protecting them and using more powerful magnets. Their presence produces an effect large compared with their apparent importance. The sketch below represents, on a large scale, one of the most highly developed of the more effective of these aneurisms, that which is situated close to the main bulb of the instrument.

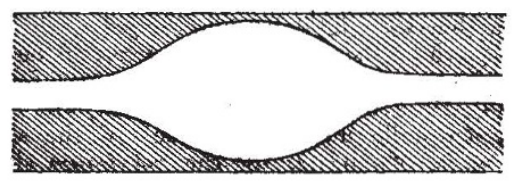

F1G. 1.-The chief Aneurism.

By reason of the convexity of the thermometer tube the diameter of the bore appears from the outside to be considerably larger than it really is. In fact a very simple geometrical construction shows that the ratio of its apparent diameter to its real diameter is that of the refractive index of glass to unity, i.e. it appears to be about $\mathrm{I} \cdot 6$ times its actual diameter. So that even when the aneurism, and the liquid filling it, appear to occupy the whole diameter of the tube, they only occupy $\frac{\mathrm{I}}{\mathrm{I} \cdot 6}$ or about two-thirds, so that even in this extreme case the walls of the aneurism are not usually very thin. The percentage diminution of volume of the middle portion of the aneurism is in such a case (roughly) 50 per cent. greater than that of the unaltered tube.

The real mischief done by the aneurism is not due mainly to thinness of the walls and consequent greater liability to distortion by pressure; it is due to the fact that the areurism, in consequence of its greater section, contains a much larger quantity of mercury than does an equal length of the tube; and therefore that a small percentage diminution of its volume will produce a marked displacement by the outflow into the narrow tube. Several of the aneurisms I have measured prcduce a disturbance of the index corresponding to that produced by at least five times their own length of the tube.

In some of the more exaggerated ones it actually produces an effect on the maximum and minimum index equal to that due to the extension of very nearly one-half of the mercury column in the thermometer. But this, though easily remediable, is not a defect of much consequence.

IX. Imploding and Exploding of the Thermometer Bulbs.In connection with the breaking of some of the thermometers, as a result of pressure whether in the press or in the sea, it may be well to describe the curious nature of the effects produced by pressure upon the material of a tube, according as the pressure is applied from without or from within.

First, $\mathrm{w}$ ith regard to the thermometers themselves, which are exposed to external pressure, but have comparatively very slight pressure applied in the interior of their bore; and second, the corresponding effect when pressure is applied, as in the press itself, from the inside and tends to stretch the walls. [This second case has occurred with one or two of the Challengtr thermometers also. Its source is usually defective strength of the terminal bulb of the maximum end of the tube. This bulb implodes, then the pressure is applied to the interior of the protected bulb, w hich, in its turn, explcdes.]

In the diagrams below, the first three figures refer to part of the walls of the glass iube, which is exposed to pressure from the outside, but has no corresponding pressure applied within.

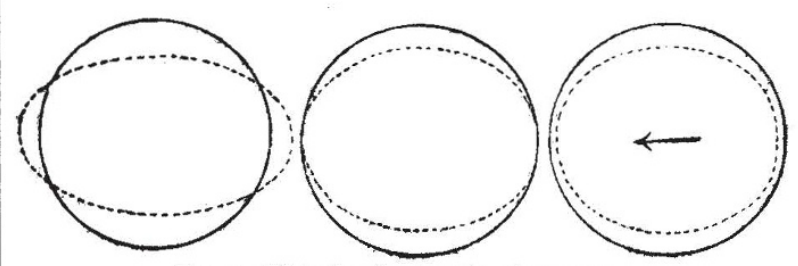

Frg. 2.-Distcrtion due to extemal pressure.

The effects of pressure indicated are those in a transverse section of the tube. The circles represent (on a large scale) transverse sections of very small spherical elements of the glass wall of the tube, the first close to the outside, the second in the middle of the wall of the tube, and the third close to the inner surface. The ellipses which are drawn along with the circles represent (of course, with much exaggeration) the corresponding transverse sections of the ellipsoids into which the spheres are distorted by the external pressure. The sphere near the outside is compressed in all directions, but much less in a radial direction than it is in a direction perpendicular to the former. The greatest amount of compression is tangential as it were, and the circular section of the sphere has been compressed into an ellipse which has a major axis in the radial direction very nearly equal to its original length, while the minor axis is very considerably reduced. The second figure refers to a small spherical portion inside the glass wall originally situated at a distance from the axis equal to 1.6 times the internal radius of the tube. (It is curious that the number $\mathbf{I} \cdot 6$, though obtained from a totally different source, should be so nearly the same as that already quoted as the refractive index of the glass.) The little spherical element at that place suffers no radial compression, but there is considerable tangential compression. Clo: $e$ to the interior surface of the glass tube we find large compression in a tangential direction and actual extension in the radial direction. These diagrams have been purfosely exaggerated to make the effects visible. They represent what would be the effect of a pressure of 650 tons weight per square incb, provided glass could stand such a pressure and still continued to follow Hooke's law ; and the outer radius of the tube has been taken as $2 \cdot 2$ times the inner. But they give all that is really required, viz. the character of the distortion at different points in the wall of the tube.

The next three figures refresent the corresponding changes in

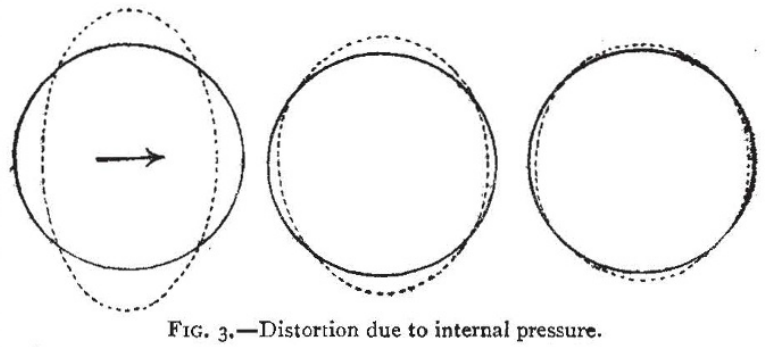

spherical elements of the same cylindrical tube exposed to pres sure from within. All portions of the tube are now extended tangentially and compressed radially, but the amount is greater on each layer as it is nearer the interior surface.

It is now easy to see how it is that a glas: tube is broken by the application of pres sure from without. The effect is, of cc urse, produced first at the interior surface. For the compression is the same for every portion of the glass, but it is accompanied by shear, which increases towards the inner surface; and it is 
probably the resulting extension which produces the effect. But $w h \geqslant n$ a tube is exposed to pressure froin the interi or there is dilatation of the walls, which aids the shear. Thus we see why a thin tube is so mach more capable of resisting external than internal pressure. It $i$ is probable that, in the case of glass, the element which first gives way is not so much cru-hed as torn asunder. If so, the tube which is conpressed from with out is in a much more fav urable condition for resisting than that in which the presiure is ajplied internally. For, in the first, the whole substance of the walls is com resed, and thus the linear extension produced by the shear is in part counteracted. In the secont, the whole substance is expa ided, and th s linear exten. sion due to the shear is aided. As will be seen in Appendix A, the case of very thick tubes is considerably different.

X. Description of the Apparatus for applying P'ressure.-Sir Wyville Thomson handed over to me, with the thermometer:, a press which was ma ie for him before he started in the Challenger, and which he had carried all round the worid; but when we made some preliminary experiments with it, we found it to be objectionable in miny ways. It was in the first place not safe at high pressures, althou sh an atceinp: hid been made to strengthen it by surrounding it with massive rings of Swedish iro:l. As the experiments had to be condusted in c.lleye, and to a great extent by students who volunteered their service; this was a fatal defect; though I believe that the danger from the bursting of a hydrostatic presi has been uiu illy very much exargerated. The bursting of the cylinder itself wou'd probably be unattended with danger; but so ne of the nuts a'd connecting pieces had occasionally been projected with great violence.

A slight numerical calculation shows that a cubic foot of water at a pressure of one ton weight to the square inch is capable of doing only about 12 Io foot lbs, of work in expanding, the reas on being that althour the pressure is intense, the amuunt of c.smpression it produces is exceedingly sinall. But a cubic fost of air at a pressure of a ton weight to the square inch is capable of doing nearly 1300 times as mush work in exp.ndiny. Hence the danger of having large quantitics of air in the press before the compression is begun.

An:ther defect of the ap;aratus was the comparatively small interior bore, which did $n$ st admit of the proper carrying out of my scheme for mea iuring pressures - the Bourdon ginuge hiving sh swn itself quite untrustiworthy. Besides, two therinometers, at most, could be exposed to pressure simultane susly, cven whe no gauge was inserted along with then

The apparatu; which Sir Wyville Thomion finally obtained from the Woolwich gun factorie, throu sh the intervention of the $\Lambda$ dmiralty, wa; in fact a Fraer gu i with a few adaltations made $t: s$ suit it to the purposes of the investigation. The gun wa; made of a cylinder of mild steel, round which were shrunk two succes ive wrought-iron c sils. The effective interior is $4 \frac{1}{2}$ inches in bore, and ne rrly 4 feet lon $r$.

This cylinder was graranteed to be safe under pressures up to 18 or 20 tons weight per square inch, and we have for various purposes already worked up to pre isures of $I 1$ and 12 tons.

The rest of the apparatus, to fit it for our immediate purpose, c.nnsisted of a tightly-fitting steel plug which was forced int: the upper end of the cylinder after the thermometers and other apparatu: had been in erted, an 1 the whole had been filled with water. The plug was forced down by the weight of an assistant standing on it, while a stop.cock at the b)ttom of the cylinder was kept open for the escape of water, until a massive steel key could be put in through a sl st in the side of the cylinder to lock the pluy in its definite position.

To the lower end of the steel cylinder were adapted a series of fittings by mean; of which it could be connecte l witb a powerful force-pump, and simultaneously with a gauge whose construction will be afterwardi describel. The gauge enabled the experimenteri to know at every stage of the operation what amount of pressure bad been renched in the interior of the cylinder. 'The pump was worked at first by hand. Of late a more powerful pump has been procured, and it can be fitted when necessary to the gas-engine of my laboratory.

Only one real difficulty was met with in working this apparatus ; viz. the difficulty of making the plug fit perfectly tight. At first, when it came from Woolwich, the plug was finished by a piece of leather in the form of a cup; but this was found to leak seriously even at very moderate pressures, so that even the comparatively small pressure of a ton weight per square inch was unattainable.

But by taking off the leather from the plug and furnishing it with a ring of steel turned into cup form with an exceedingly thin and sharp ed ,e, o. the sume p:inci le a; that on which the piston of the pump wa; co.1 tructel, this diffi sulty wa : c snpletely gut ,ver. The flexible steel ed se was presied against the interior of the tu'se $m$ sre forcibly the greater the applied presisure, and it was found that the ap,aratu; was then, except under the most unfavourable circimstances, perfectly tight, at least so far as the plug was concerned. Very great cure wa, however, requisite in cleaning the plug ant the upper part of the $b$ re of the cylinder befure each experiment. The smullest fra rment of cotton-waste, getting behind the elge of the cup, almost invariably produced seriou; le ak age when high pressure was applied. The cup form was objectionable for one reason, that it always took down a c.msiderable quuntity of air, of which it was im so ssible to get rid. This difficulty was overc me by putling into the cup a quantity of tall ww which comoletely filled it us and projected c.onsiderably bel w it, so that the aipparatu;, when pressure commenced, contained at the most a few small air bubbles only.

Later, when I found it was impossible t) obt rin certain nece;sary data, on account of the sl wne is with which pressure was got up in so large an app uratu;, I procured a very much smaller apparatus of simil ur character, in which the cylinder was only an inch in $b$ re, and rather less than a foot in effective interior length. With thi; appuratu; tws or three stroke; only, of the puinp were required $t$, get $u$, the desired presiure, an't there wa; the grest addition al advant ige that teanperatures could be inde,en lently measure l by mean; of ther.m relectric junctions. [This $\mathrm{c}$ suld not be do:e in the larye cylinder withou: seriou:ly affecting its strength, and rendering it at the same time almost unmanageable.]

( $T o$ be continued.)

\section{TRANSFORMATION OF OLD COINS IN A \\ LAKE}

M DAUBRÉE rea 1 an interestin y paper on this su'pject at the Pari; Academy of Science; on Ostober 17.

In the csmmune of Flines-le:-Roches, canton of Douai, there is a snall lake of very limpid water, known as the Mer-deFlines. It is of circular shape, ant about $300 \mathrm{~m}$. in dianeter; its surface remains stationary in position, and neither s rings supplying it, $\mathrm{n}$ )r any outlet, are apparent. The depth at the centre has not been ditermined. Thore are fishes in the lake, and the water attracts numerous bather:. Amony other shell; on the banks, one observes many specimens of Unit. The water rests on Tertiary strata of the Landenian formation, consisting of sand and gravel, with dark ashes and pyrites.

According to the researches of MM. Terinink and Loustan, this lake appears to have been, in ancient time;, a place of sacred resort, and varions precious objects we:e thrown into it, as an offering doubtless to some divinity. Numerou; coins, more especially, havc been recovered, along with statuettes of bronze and much pottery dibris. Of the coins, some are Gaulish, but the majority are Roman, of the time of the early Empire. They are mostly bronze, but some are of gold.

Some remarkable change; have occurre 1 in many of these coin:, and have been brought to the notice of the French Academy by M. Daubrée. The coin; have been attacked and are completely enveloped with a crystalline substance formed at their cxpense. Their general aspect recalls that of the coins incrusted with metallic mineral; , found in various thermal springs, notably at Bagnères-de-Bigorse, at Bourbonne-les-Bains, and at Baracci in Corsica.

An cxtremely fine external pellicle, of the brass-yellow colour which characterises chalcopyrite, first attracts notice. But the incrustation is mostly formed, to a depth of $2 \mathrm{~mm}$., of a dark crystalline substance, with metallic lustre, consisting of sulphide of copper, and it is to it that the crystalline forms belong, which one might be apt, at first sight, to attribute to yellow sulphur.

The central part consists of a laminated substance. Here and there may be observed small dark hexagonal metallic crystali, in which one can see the characteristic strix of chalcocitc. The same substance forms small brilliant leave;, alternating with the dark leaves, on which appear some deposits of bright green. Heated in 2 tube, the crystalline substance gives a very slight sublimate of sulphur, which apparently results from the mixture of a little pyrites. The sulphide contain's neither tin nor zinc.

The form of the exterior substance is that of hexagonal plates. bearing truncated pyramidal faces inclined about $127^{\circ}$ to the base. The cleavage is basic. This latter character and the 